\title{
TRAID-seq: Unbiased analysis of RNA tailing enzyme activity at single- nucleotide resolution
}

Marvin Wickens ( $\square$ wickens@biochem.wisc.edu )

Dept of Biochemistry, University of Wisconsin, Madison

Melanie A. Preston

Dept of Biochemistry, University of Wisconsin, Madison; Current Address: Promega Corporation, Madison, Wl; Current address: Promega Corporation, Madison, WI https://orcid.org/0000-0002-0735-0754

Douglas F. Porter

Dept of Biochemistry, University of Wisconsin, Madison; Current address: Stanford University Medical School, Stanford, CA

Fan Chen

Dept of Statistics, University of Wisconsin, Madison

\section{Natascha Buter}

Dept of Biochemistry, University of Wisconsin, Madison; Current Address: Promega Corporation, Madison, Wl; Current address: Promega Corporation, Madison, WI

Christopher P. Lapointe

Dept of Biochemistry, University of Wisconsin, Madison; Current address: Stanford University, Stanford CA

Sunduz Keles

Dept of Statistics, Dept of Biostatistics and Medical Informatics, University of Wisconsin, Madison

Judith Kimble

Dept of Biochemistry, Dept of Genetics, University of Wisconsin, Madison

\section{Method Article}

Keywords: Ribonucleotidyl transferase, RNA tailing enzymes, rNTases, poly(UG)polymerase, poly(A)polymerase, PAP, poly(U)polymerase, PUP, CCA-adding enzyme, TRAID-Seq

Posted Date: May 22nd, 2019

DOI: https://doi.org/10.1038/protex.2019.016

License: (c) (i) This work is licensed under a Creative Commons Attribution 4.0 International License. Read Full License 


\section{Abstract}

Ribonucleotidyl transferases $\backslash$ (rNTases) add non-templated ribonucleotides to diverse RNAs. We developed a screening strategy in S. cerevisiae to identify sequences added by candidate enzymes from different organisms at single-nucleotide resolution. The assay, referred to as TRAID-Seq $\backslash$ (tethered rNTase activity identified by high-throughput sequencing), circumvents the need for purified enzymes, which can be problematic with rNTases, and precisely identifies many thousands of independently captured tail sequences, enabling a sensitive determination of their sequences and relative abundances. The rNTase activities of 19 previously unexplored enzymes were determined using TRAID-Seq. In addition to poly $\backslash(A)$ - and poly $\backslash(U)$-adding enzymes, we identified a Cadding enzyme that is likely part of a two-enzyme system that adds CCA to tRNAs in a eukaryote; a nucleotidyl transferase that adds nucleotides to RNA without apparent nucleotide preference; and a poly $(U G)$ polymerase, C. elegans MUT-2, which adds alternating $U$ and $G$ nucleotides to form poly $\backslash(U G)$ tails. MUT-2 is known to be required for certain forms of RNA silencing, and mutations in the enzyme that are defective in these functions also fail to add poly $\backslash($ UG) tails in our assay, thus implicating poly $($ UG) polymerase activity in genome integrity and RNA silencing.

\section{Introduction}

See figure in Figures section. **Figure 1. TRAID-Seq assay measures nucleotide addition activity in vivo.** $\backslash(a, b)$ TRAID-Seq strategy. $\backslash(a)$ tRNA ${ }^{\text {Ser }(\text { (AGA) }}$ variable arm \(gray) is mutated to an MS2 stem loop \(cyan) to form the tRNA reporter. \(b) Left, tRNA reporter is co-expressed with an MS2 coat proteinrNTase fusion in _S. cerevisiae_. The tethered rNTase adds nucleotides to the $3 囚$ end of the tRNA. Right, RT-PCR analysis to detect A tails or U tails added by control rNTases, relative to empty vector or a no-reporter control. Lanes marked with a dash indicate reactions performed without reverse transcriptase. Representative gel image from 4 independent experiments. \(c) Schematic of sample processing. DNA adapter $\backslash$ (dark blue) with random heptamer $\backslash(N 7$, orange) is ligated to total RNA extracted from samples, followed by reverse transcription, PCR, and high-throughput sequencing. $\backslash(\mathrm{d}$, e) Tail-o-grams of nucleotides added by control rNTases. Data are shown for_C. elegans_PUP-2 $\backslash$ (d) and_C. elegans_GLD-2 $\backslash($ e). Percent of each nucleotide at each tail length is color-coded and plotted on the left y-axis; $U \backslash$ (green), $C \backslash$ (yellow), G \(purple), A \(brown). The number of tails detected per million random heptamers $\backslash$ $(\mathrm{TPMH})$ are indicated by gray diamonds and correspond to the log scale on the right $y$-axis.

\section{Procedure}

**TRAID-Seq Protocol****A. Clone rNTase/enzyme of interest into MS2 cassette vector** 1 . Clone gene corresponding to rNTase/enzyme of interest using multiple cloning site in MAP72 _2 $\mu$ LEU2_ MS2 cassette vector. Notes: $\backslash(1)$ Verify that the chosen restriction enzymes do not cut within the coding sequence of your gene of interest. \(2) When designing primers for gene amplification, be sure to remove the stop codon of the gene of interest. A stop codon is included in the construct after the $\backslash(\mathrm{RGS}) \mathrm{His}_{6}$ tag. 2. As a negative control, create a construct in which putative catalytic residues are mutated. As an example, for candidate rNTases, mutate predicted catalytic aspartic acids to alanine. Figure 2: Annotated Sequence of MS2 Cassette \(MAP72 $2 \mu$ LEU2 MS2 cassette vector) See figure in Figures section. Sequence only $\backslash$ (vector backbone indicated with bold) $\star \star t$ tcacacaggaaacagctatgaccatgattacgcca** agcttACAATGCATACTTTGTACGTTCAAAATACAATGCAGTAGATATATTTATGCATATTACATATAATACATATCACATAGGAAGCAACAGGCGCGTTGGACTTTTAATTTTI **actggccgtcgttttacaacgtcgtgactgg** Primers to sequence inserted gene of interest: MS2cassette-seq 5': 5' CACGAATTCCGACTGCGAGCT 3' MS2cassette-seq 3': 5' CAACGTATCTACCAACGATTTGACC 3' **B. Transform rNTase and tRNA reporter into BY4741 yeast** 1 . Inoculate YPD media with BY4741 and incubate at $30^{\circ} \mathrm{C}$ overnight with shaking. 2. Calculate the amount of cells to use for transformations. Need $1.67 \mathrm{OD}_{600}$ per transformation $3 . \mathrm{Measure}^{\mathrm{O}} \mathrm{OD} \mathrm{D}_{600}$ of $1 / 50$ dilution \(in YPD) from overnight culture. 4. Transfer the appropriate volume of culture to a new sterile tube. 5 . Centrifuge at $4000 \mathrm{rpm}$ for 5 minutes at room temperature 6. During centrifugation, prepare appropriate amount of One Step Buffer $\backslash(50 \mu$ l of One Step Buffer per transformation). Prepare fresh each time. Due to viscosity of PEG, be sure to prepare extra volume. See figure in Figures section. 7. Remove supernatant and resuspend cell pellet in One Step Buffer by gently pipetting up and down. For example, $600 \mu \mathrm{L}$ of One Step Buffer is needed for 12 transformations. 8. Add appropriate volume of salmon testes single stranded DNA \(Sigma-Aldrich D7656-1ML) to the cell/One Step Buffer mixture $\backslash(2.5 \mu \mathrm{L}$ per transformation). For example, add $30 \mu \mathrm{L}$ of salmon testes single stranded DNA for 12 transformations. 9. Mix by gently pipetting up and down 10. To a 1.5ml eppie tube, add 0.5 $\mu \mathrm{L}$ of miniprep DNA $\backslash(100-400 \mathrm{ng} / \mu \mathrm{L})$ corresponding to tRNA reporter \(MAP80A_2 $\mu$ URA3_tRNA ${ }^{\text {Ser }(A G A)}$ with MS2 stem loop in variable arm in tRNA ${ }^{\text {His }}$ cassette) and $0.5 \mu \mathrm{L}$ of miniprep DNA $\backslash(100-400 \mathrm{ng} / \mu \mathrm{L})$ corresponding to the rNTase construct to test. 11. Add $50 \mu \mathrm{L}$ of cells/One Step Buffer/salmon testes DNA mixture to each tube. Tap mix immediately after adding the cell mixture. 12 . Heat shock at $45^{\circ} \mathrm{C}$ for 35 minutes. 13 . Add 75 uL YPD to each tube and mix. 14 . Plate $30 \mu \mathrm{L}$ onto SD-Ura-Leu plates. 15 . Incubate at $30^{\circ} \mathrm{C}$ for $3-5$ days. ${ }^{\star \star} \mathrm{C}$. Grow yeast to log phase and harvest** 1 . Inoculate $5 \mathrm{~mL}$ of SD-Ura-Leu with a single colony resulting from the transformation above. 2 . Grow at $30^{\circ} \mathrm{C}$ with shaking for approximately 24 hours. Cultures should reach saturation. 3. Use this culture to start $50 \mathrm{~mL}$ cultures of each sample in SD-Ura-Leu at OD600=0.15. 4 . Grow to log phase $\backslash\left(\mathrm{OD}_{600}=0.8-1.0\right)$. 5. Put the flasks on ice for about 5 minutes to chill the cultures. 6 . Transfer culture to $50 \mathrm{~mL}$ conical tubes, taking note of the final volume. Multiply the volume by the OD600 reading to calculate the number of cells harvested. 7 . Centrifuge at $3000 \mathrm{rpm}$ in a table top centrifuge for 10 minutes. 8. Wash pellet by resuspending with $2 \mathrm{~mL}$ of cold ddH2O 9. Transfer an equal volume $\backslash(\sim 1 \mathrm{~mL})$ into each of two $2 \mathrm{~mL}$ eppie tubes to produce 2 pellets. Note: One pellet will be used to confirm expression of the protein of interest, and the other will be used to extract RNA. 10. Centrifuge at 5000 rpm in microfuge at $4^{\circ} \mathrm{C}$. 11 . Remove and discard supernatant. 12. Freeze pellets on dry ice. 13 . Store at $-80^{\circ} \mathrm{C}$ until ready to process. ${ }^{* * D}$. Verify expression of rNTase/enzyme of interest by Western Blotting** ESB Buffer: See figure in Figures section. 1. Resuspend cell pellet in $30 \mu \mathrm{L}$ of ESB buffer. 2 . Heat to $100^{\circ} \mathrm{C}$ for 3 minutes. Cool slightly $\backslash$ (enough to handle tubes). 3. Carefully open the lid, and add $425-600 \mu \mathrm{m}$ glass beads $\backslash$ (Sigma G8772) to saturate sample $\backslash$ (about 0.1 g). 4. Vortex for 2 minutes. 5. Add $70 \mu \mathrm{L}$ of ESB buffer, vortex briefly. 6 . Heat to $100^{\circ} \mathrm{C}$ for 1 minute. 7 . Load lysate corresponding to $1 \mathrm{OD}_{600}$ of cells onto a 4 $15 \%$ SDS-PAGE gel. Use total $\mathrm{OD}_{600}$ calculated from cultures to determine the volume to add. 8 . Transfer to an activated PVDF membrane for Western blotting. 9. Block in $1 \mathrm{X}$ TBS/0.1\% Tween/5\% BSA \(TBST/BSA) for 1 hour at room temperature. Blocking with milk $\backslash$ (even after blot stripping) will result in a high background for the anti-enolase antibody. 10. For a loading control, incubate with rabbit anti-enolase antibody $\backslash($ Cell Signaling \#8171 Enolase-2 D20H2 rabbit). 11. Wash $3 x$ with TBST at room temperature for 10 minutes each. 12. Incubate with goat anti rabbit antibody 1/15,000 dilution in TBST/BSA at room temperature for $1 \mathrm{~h}$ with shaking. 13. Wash $3 \mathrm{x}$ with TBST at room temperature for 10 minutes each. 14. Image blot. 15. Following imaging, strip the blot and 
prepare to reprobe with anti-RGSHis antibody \(5-Prime/Qiagen Cat No./ID: 34610). 16. Block in 1X TBS 0.1\% Tween \(TBST)/5\% milk for 1 hour at RT. 17. Incubate with $1 / 2500$ dilution of mouse anti RGS-His antibody for 1 hour at room temperature. 18 . Wash $3 x$ with TBST at room temperature for 10 minutes each. 19. Incubate with $1 / 10,000$ dilution of goat anti mouse antibody for 1 hour. 20 . Wash $3 x$ with TBST at room temperature for 10 minutes each. 21 . Image blot to confirm expression of each rNTase/enzyme of interest. 22. Proceed only with samples from which rNTase/enzyme of interest is detected. **E. Extract total cellular RNA** Needed per sample: $1.25 \mathrm{~mL}$ ISO Buffer $2 \mathrm{~mL}$ Phenol/Chloroform/Isoamyl Alcohol $\backslash(25: 24: 1 \mathrm{Mixture}$, pH 6.7). Referred to as PCA in the protocol below. 1. Prepare RNA ISO Buffer. See figure in Figures section. a. Dissolve SDS in DEPC-treated water. Then add to remaining buffer ingredients. b. Filter sterilize with $0.2 \mu \mathrm{m}$ filter. Note: RNA ISO Buffer can be made ahead and stored at room temperature. If SDS precipitates, buffer can be warmed at $65^{\circ} \mathrm{C}$ for 10 minutes to resuspend, but the buffer must cool to room temperature prior to using in extraction. 2 . Resuspend cell pellet in $0.5 \mathrm{~mL}$ RNA ISO buffer. 3 . Add $0.5 \mathrm{~g}$ of $425-600 \mu \mathrm{m}$ glass beads $\backslash$ (Sigma G8772) to each tube. Make sure that the glass beads used are reserved only for RNA purification in order to avoid RNase contamination. 4. Add $0.5 \mathrm{~mL}$ PCA $\backslash(25: 24: 1)$ to each tube. Wrap tops of tubes in parafilm to prevent tubes from popping open during vortexing. 5. Vortex for 20 seconds then place on ice. Repeat this process for a total of 10 times. 6 . Quick-spin tubes to bring volume out of the tube lid. 7. Transfer as much of the volume as possible into two new $1.5 \mathrm{~mL}$ eppie tubes. Make sure that the volume in each of the two new tubes is equal. 8 . Add $0.375 \mathrm{~mL}$ RNA ISO buffer to each tube. 9 . Add $0.375 \mathrm{~mL}$ PCA $\backslash(25: 24: 1)$ to each tube. 10 . Mix by inverting the tubes. 11 . Centrifuge at maximum speed in a microfuge at $4^{\circ} \mathrm{C}$ for 10 minutes. 12. During the sample centrifugation step, centrifuge Phase Lock Gel Heavy $\backslash(P L G H)$ tubes $\backslash(Q u a n t a B i o / 5 P R I M E)$ at maximum speed for 5 minutes at room temperature. Note: One PLGH tube is needed per starting sample. Aqueous layer from the 2 tubes will be recombined into the PLGH tube. 13. Transfer aqueous phase into 1 pre-spun PLGH tube per sample $\backslash$ (combine the 2 tubes per sample). 14 . Add 0.75 mL PCA \(25:24:1). If the entire volume of PCA doesn't fit into the tube, just fill as much as possible so that the tube can still close. 15. Invert tube to mix. 16. Centrifuge at maximum speed at room temperature for 5 minutes. 17. Transfer aqueous phase into two new $2 \mathrm{~mL}$ eppie tubes. Make sure that the volume in each of the two new tubes is equal. 18. Add $1 \mathrm{~mL}$ of $100 \%$ ethanol to each tube. 19 . Mix gently. 20. Incubate on dry ice for 20 minutes or at $-80^{\circ} \mathrm{C}$ for 1 hour to overnight. 21 . Centrifuge at maximum speed in a microfuge at $4^{\circ} \mathrm{C}$ for 10 minutes. 22. Remove and discard supernatant. 23. Dissolve each pellet in $25 \mu \mathrm{L}$ of DEPC-treated water. 24 . Combine the 2 tubes per sample into 1 tube. Proceed with DNase treatment Note: The following DNase treatment protocol is optimized to digest overexpressed plasmid DNA corresponding to the tRNA reporter. This amount of DNase is needed because downstream amplification steps target a sequence in the tRNA reporter that is also in the DNA used for expression. 25. Prepare appropriate volume of DNase mix needed for all samples following the recipe below. See figure in Figures section. 26. Add $50 \mu \mathrm{L}$ of DNase mix to each sample. 27. Incubate at $37^{\circ} \mathrm{C}$ for 4 hours. 28. Clean up RNA with GeneJET RNA Purification Kit $\backslash($ ThermoFisher). a. Add $300 \mu \mathrm{L}$ of Lysis Buffer to DNase reactions and mix by pipetting. b. Add $180 \mu \mathrm{L}$ of $100 \%$ ethanol and mix by pipetting. C. Transfer sample to GeneJET RNA purification column. d. Centrifuge at maximum speed for 1 minute. Transfer each column to a new $2 \mathrm{~mL}$ collection tube. e. Add $700 \mu \mathrm{L}$ of Wash Buffer 1. Centrifuge at maximum speed for 1 minute. f. Add $600 \mu \mathrm{L}$ of Wash Buffer 2. Centrifuge at maximum for 1 minute. g. Add $250 \mu \mathrm{L}$ of Wash Buffer 2. Centrifuge at maximum for 2 minute. h. Discard flowthrough and centrifuge again at maximum for 1 minute. i. Add $50 \mu \mathrm{L}$ of DEPC-treated water. Centrifuge at maximum speed for 1.5 minutes. 29. Measure concentration. 30 . Store at $-80^{\circ} \mathrm{C}$ in aliquots to avoid freeze-thawing. ${ }^{* *}$. Ligate Adapter** AppN7-RNATruSeq3'Adapter: 5 AppNNNNNNN TGGAATTCTCGGGTGCCAAGG ddC $3^{\prime}$ **Important note:** Adenylated adapter must be PAGE gel purified to ensure that all adapter added into the ligation reaction is adenylated. PAGE purification or HPLC purification offered by IDT is not sufficient to remove all unmodified adapter. This was confirmed by discussions with IDT Technical Support, as the resolution of their methods is not precise enough for this application, partially due to the variable size of the random heptamer. ${ }^{*}$ PAGE purification of adenylated adapter** 1 . Prepare a $20 \%$ acrylamide $8 \mathrm{M}$ urea, $1.5 \mathrm{~mm}$ thick sequencing-length gel using the SequaGel - UreaGel System \(National Diagnostics). Length of gel is key to ensure single nucleotide resolution. 2. Pre-run gel and load $8 \mathrm{nmol}$ of adapter. Also load 5 pmol of unmodified adapter and $1 \mu \mathrm{L}$ of $10 \mathrm{bp}$ DNA Step Ladder $\backslash$ (Promega Corporation). 3. Run gel until 10 bp band is $1 / 3$ of the way down the gel $\backslash$ (bromophenol band in loading dye should run off the gel). 4. Stain with 1:20,000 dilution of SYBR Gold Nucleic Acid Gel Stain $\backslash($ ThermoFisher) in $1 x$ TBE for 10 minutes. 5. Return gel to glass plate and wrap in plastic wrap. 6. UV-shadow band with short-wave UV $\backslash$ (to use a sharpie to mark the adenylated adapter band on the plastic wrap). 7. Use a razor blade to trace the marked plastic wrap and cut the band out of the gel. To increase gel extraction efficiency, cut the gel band in half. 8 . Transfer each gel piece into its own $3 \mathrm{~mL}$ syringe 9 . Use the syringe plunger to crush the gel piece into a Falcon 2059 round bottom tube. 10. Add $1.6 \mathrm{~mL}$ of Gel Elution Buffer $\backslash$ (recipe below can be made ahead of time and stored at room temperature). See figure in Figures section. 11. Parafilm lids of tubes and incubate overnight at $37^{\circ} \mathrm{C}$ with gentle shaking. 12. After overnight incubation, add ammonium acetate to $2 \mathrm{M} \backslash(480 \mu \mathrm{L}$ of $5 \mathrm{M}$ ammonium acetate to each tube). 13. Centrifuge tube at $1000 \mathrm{rpm}$ for 2 minutes to pull all volume to the bottom of the tube 14. Add all liquid and gel to empty Biospin column $\backslash$ (Bio-Rad) in a 2059 Falcon tube to separate liquid from gel. 15. Centrifuge for 5 minutes at 2500 rpm in table top centrifuge. 16. During centrifugation step, pre-spin four $2 \mathrm{~mL}$ PLGH tubes. 17. Transfer cleared liquid to pre-spun PLGH tubes $\backslash$ (about $0.75 \mathrm{~mL}$ per tube), taking note of total volume. 18 . Add 0.75 $\mathrm{mL}$ of PCA pH 6.7. Mix by inverting tubes. 19. Centrifuge at maximum speed at room temperature for 5 minutes. 20. Transfer aqueous layer to 2 new 2059 Falcon tubes. 21 . Add $2 X$ volume of $100 \%$ ethanol. 22. Incubate for 15 minutes on dry ice $\backslash$ (or overnight at $-20^{\circ} \mathrm{C}$ ). 23 . Centrifuge for 45 minutes at 5000 rpm in a table top centrifuge. 24. Remove and discard supernatant. 25. Wash pellets with $70 \%$ EtOH. 26. Centrifuge for 45 minutes at 5000 rpm in a table top centrifuge. 27. Remove all liquid $\backslash$ (do not need to dry pellet, but can dry for a maximum of 10 minutes before resuspension). 28 . Resuspend each pellet in 40 $\mu \mathrm{L}$ of TE pH 8.0. 29. Measure concentration and calculate as pmol/ $\mu \mathrm{L}$. 30 . Store at $-80^{\circ} \mathrm{C}$ in $5 \mu \mathrm{L}$ aliquots. 31 . To check purification, run $5 \mathrm{pmol}$ on $20 \% \mathrm{PAGE}$ gel, $8 \mathrm{M}$ urea. Also run $5 \mathrm{pmol}$ of unpurified adapter, $5 \mathrm{pmol}$ of unmodified adapter and $1 \mu \mathrm{L}$ of $10 \mathrm{bp}$ DNA Step Ladder $\backslash$ (Promega Corporation). See figure below. 32. Stain with SYBR Gold $\backslash\left(1 / 20,000\right.$ in $1 \times$ TBE) for 10 minutes and image. See figure in Figures section. ${ }^{*}$ Ligation Reaction ${ }^{\star *} 1$. Dilute each RNA sample to $100 \mathrm{ng} / \mu \mathrm{L} \backslash$ (will use $100 \mathrm{ng}$ for ligation). 2. Prepare volume of reaction mix appropriate for the number of ligation reactions. T4 RNA Ligase 2, truncated KQ \(NEB) reaction mix See figure in Figures section. 3. Add $19 \mu \mathrm{L}$ of reaction mix to each tube. 4 . Add $1 \mu \mathrm{L}$ of yeast total RNA $\backslash(100 \mathrm{ng})$. 5. Incubate overnight at $16^{\circ} \mathrm{C}$. 6. Proceed with reverse transcription or store at $-20^{\circ} \mathrm{C}$. ${ }^{\star *} \mathrm{G}$. Reverse transcribe to form cDNA* 1 llumina RNA RT primer $\backslash(15013981)$ : $5^{\prime}$ GCCTTGGCACCCGAGAATTCCA 3' 1. Dilute Illumina RNA RT primer to $5 \mathrm{pmol} / \mu \mathrm{L}$ in TE buffer. 2 . In a $0.2 \mathrm{~mL}$ PCR tube, combine $1 \mu \mathrm{L} \backslash(5 \mathrm{pmol})$ of RNA RT primer with $10 \mu \mathrm{L}$ of ligation reaction from above. Mix. 3. Incubate at $70^{\circ} \mathrm{C}$ for 5 minutes in a thermal cycler. 4 . Immediately chill on ice for at least 5 minutes. 5. Prepare the following mix for ImProm-II Reverse Transcriptase $\backslash$ (Promega Corporation): See figure in Figures section. 6 . Add $9 \mu \mathrm{L}$ of RT mix to each RNA/primer mix. 7. Program a thermal cycler for the following incubations. 8. Incubate at $25^{\circ} \mathrm{C}$ for 5 minutes to anneal. 9 . Incubate at $42^{\circ} \mathrm{C}$ for 1 hour to extend. 10 . Incubate at $70^{\circ} \mathrm{C}$ for 15 minutes to inactivate the reverse transcriptase. 11 . Store reactions at $-20^{\circ} \mathrm{C}$ or proceed with PCR amplification. ${ }^{*} \mathrm{H}$. PCR amplify and add Illumina TruSeq sequences and barcode ${ }^{\star \star} 5^{\prime}$ primer: $5^{\prime}$

Page $3 / 9$ 
AATGATACGGCGACCACCGAGATCTACACGTTCAGAGTTCTACAGTCCGACGATCGAGGATCACCCATGTCGCAG 3' 3' Primer = RNA PCR Primer 5' CAAGCAGAAGACGGCATACGAGAT \[NNNNNN] GTGACTGGAGTTCCTTGGCACCCGAGAATTCCA 3' \[NNNNNN] = Illumina RPI sequence for barcoding. A different index primer should be used for amplification of each sample. Expected product: $>167$ bp \[29 \(Illumina $\left.5^{\prime}\right), 26 \backslash\left(5^{\prime}\right.$ adapter) + 41 \(tRNA) + added tail + $28 \backslash($ N7 3' adapter $)+43 \backslash$ (barcode +3 ' Illumina seq) $)$ **Prepare 4 reactions per sample for RT reactions. Only 1 reaction per RNA ligation control is needed. ${ }^{\star *}$ See figure in Figures section. ${ }^{\star *}$ Perform the following steps at room temperature** 1 . Prepare reaction mix for all components except for template and 3' primer. 2. Add barcode primer to each of 4 tubes per sample. 3. Add $1 \mu \mathrm{L}$ of RT reaction to each of 4 tubes per sample. Add RNA ligation/water to 1 tube per sample. 4 . Add $10.88 \mu \mathrm{L}$ of reaction mix to each tube. Mix. 5. Run the following PCR protocol: See figure in Figures section. 6 . Pool the 4 PCRs for each sample into 1 tube. 7. Run $4 \mu \mathrm{l}$ of each sample on a $2.5 \%$ agarose gel to check products. 8 . Store remaining sample at $-20^{\circ} \mathrm{C}$. ${ }^{\star *}$. Gel purify tRNA reporter with tails ${ }^{\star \star}$ 1. Prepare a $20 \%$ acrylamide $8 \mathrm{M}$ urea, $1.5 \mathrm{~mm}$ thick sequencing-length gel using the SequaGel - UreaGel System $\backslash($ National Diagnostics). Length of gel is key to ensure sufficient resolution. 2. Pre-run gel. 3. Load entire volume of PCR for each sample. Also load 50bp Step Ladder \(Promega Corporation) and $1 \mathrm{~Kb}$ Ladder $\backslash$ (Promega Corporation). Because bands will run off the gel, both ladders are needed to verify the identity of the bands. 4 . Run gel until bromophenol blue band in loading dye just runs off the gel. 5. Stain with 1/20,000 dilution of SYBR Gold Nucleic Acid Gel Stain $\backslash$ (ThermoFisher) in $1 x$ TBE for 10 minutes. 6. Image the gel using fluorescence detection methods to determine where to cut the gel for each sample. ${ }^{\star *}$ Important Note: ${ }^{*}$ The goal is to cut out the tail added to the mature tRNA and a small portion of the mature tRNA. Cutting too far above the mature tRNA PCR band will result in pre-tRNA being brought through the purification, which will reduce the amount of reads generated for tailed mature tRNA. In initial tests and earlier version of computational analyses, tails were observed on the pre-tRNA, but its processing was atypical and difficult to predict sample to sample. Most consistent results were obtained when focusing analyses on the mature tRNA. See example image below for guidance on cutting out gel bands. See figure in Figures section. 7. Return gel to glass plate and wrap in plastic wrap. 8. Place glass plate and gel on a UV box and use a sharpie to mark the adenylated adapter band on the plastic wrap. 9 . Use a razor blade trace the marked plastic wrap and cut each band out of the gel. 10. Transfer each gel piece into its own $3 \mathrm{~mL}$ syringe. 11 . Use the syringe plunger to crush the gel piece into a Falcon 2059 round bottom tube. 12. Add $450 \mu \mathrm{L}$ of TRAID-Seq Gel Elution Buffer $\backslash$ (recipe below can be made ahead of time and stored at room temperature). As compared to the elution buffer used above, this recipe increases ammonium acetate to $1 \mathrm{M}$, and it omits EDTA and SDS, as those reagents negatively affect Illumina sequencing. See figure in Figures section. 13 . Parafilm lids of tubes and either store overnight at $-20^{\circ} \mathrm{C} \backslash(\mathrm{can}$ also be stored over a weekend) or proceed with elution. 14. Incubate at $37^{\circ} \mathrm{C}$ with gentle shaking for at least 4 hours. 15 . Centrifuge tubes at 1000 rpm for 2 minutes to pull all volume to the bottom of the tube 16 . Separate gel from buffer using empty Bio-Rad Micro BioSpin columns. a. Put spin column in $2 \mathrm{~mL}$ eppie tube. b. Pour gel/buffer mix into column. c. Centrifuge at $4000 \mathrm{rpm}$ in a standard microfuge at room temperature for 4 minutes. d. Discard column and proceeded to next step with eluate. 17. During centrifugation step, pre-spin one $2 \mathrm{~mL}$ PLGH tube per sample $\backslash$ (maximum speed at room temperature for 5 minutes). 18. Transfer eluate to pre-spun PLGH tube, taking note of total volume $\backslash(\sim 400 \mu \mathrm{L})$. 19. Add equal volume of PCA pH 6.7, and mix. 20. Centrifuge at maximum speed at room temperature for 4 minutes. 21. Repeat steps 19 and 20. 22. Transfer aqueous layer to a new $1.5 \mathrm{~mL}$ eppie tube. 23 . Add equal volume of chloroform $\backslash(\sim 350 \mu \mathrm{L})$, and mix. 24. Centrifuge at maximum speed at $4^{\circ} \mathrm{C}$ for 10 minutes. 25. Transfer supernatant to new $1.5 \mathrm{~mL}$ eppie tube. 26 . Repeat steps 23-25. 27. Add 2.25x volume of $100 \% \mathrm{EtOH} \backslash(\sim 790 \mu \mathrm{L})$. 28. Incubate for 15 minutes on dry ice or overnight at $-80^{\circ} \mathrm{C}$. 29 . Centrifuge at maximum speed at $4^{\circ} \mathrm{C}$ for 30 minutes. 30. Remove supernatant. 31 . Wash with $500 \mu \mathrm{L}$ of cold $70 \%$ ethanol. 32 . Centrifuge at maximum speed at $4^{\circ} \mathrm{C}$ for 15 minutes. 33 . Remove all liquid $\backslash$ (do not need to dry pellet, but it is important to remove all ethanol before resuspension). 34 . Resuspend with $10 \mu \mathrm{L}$ of nuclease-free ddH2O. 35. Measure concentration Note: Nanodrop can be used but results in an inaccurate estimation of concentration. Quantitation of concentration by using a fluorescent DNA binding dye, such as QuantiFluor ONE dye \(Promega Corporation), is more accurate and will produce more equal representation of each sample. 36. Combine all samples at an equal concentration \(ideally $1 \mathrm{ng} / \mu \mathrm{L}$ each sample). Note: Due to the number of multiplexed samples, $1 \mathrm{ng} / \mu \mathrm{L}$ will likely not be achievable. Combine in such a way that each sample is at its highest possible concentration in the final mixed population. ** J. Paired-end sequencing** Use Illumina paired-end sequencing of at least $2 \times 50$ bp $\backslash(2 \times 100$ bp has also been used $)$ to generate sequencing data. TRAID-Seq sample have been run on a HiSeq2000 and HiSeq2500. The target number of reads per sample is 1 million. Depending on the diversity of the tails added to the tRNA, more than 1 million reads may result in longer computational time to remove PCR duplicates. Important consideration: Read 1 will always have the same sequence for the first $\sim 40$ nucleotides. For high-quality sequencing, it is best to mix TRAID-Seq samples with a sample or samples that have diverse sequences. If such experimental sample are not available, PhiX can be used. TRAID-Seq samples have been successfully run in the control lane of a HiSeq2000 or HiSeq2500. It

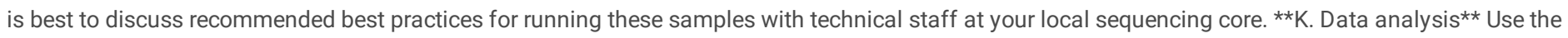
PuppyTails suite of programs to analyze data. Programs are freely available here: https://github.com/melanieapreston/PuppyTails Depending on the number of data files and size of files, it might be most efficient to analyze data via a Linux-based computational server $\backslash$ (rather than a single Linux-based PC) in sets

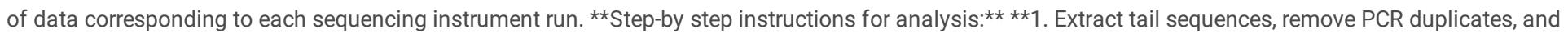
count number of uniquely observed tails. ${ }^{\star \star}$ Copy extract_inserts.py to appropriate directory Navigate to appropriate directory python extract_Tails.py Program may take several hours to run on a computational server, depending upon the dataset file sizes. Output: Inserts folder containing one inserts file $\backslash$ (Samplename.fastq.inserts) per sample with 3 data columns: 1. 3' end of the tRNA reporter 2. added tail sequence 3 . number of times observed $* \star 2$. Analyze tail sequences to determine percentages of each nucleotide at each tail length and generate tail-o-grams. ${ }^{\star \star}$ Once the .inserts files are generated, the next step of analysis is to use the analyzeTails.py program: python analyzeTails.py $-0-n-p$ Details on the added options: -0 will only use tails with a CCA end. $-n$ will normalize to dataset size $\backslash$ (per 1 million). - $p$ will output values as percents. This program can take up to an hour to run on a computational server, depending on size of .inserts files and the number of files to analyze. Outputs: -tables folder containing text files of the most commonly observed tail sequences -figs folder containing tail-o-grams for each sample -dataForGraph.txt file containing percent of each nucleotide at each observed tail length, and number of unique tails observed at each tail length Data generated from these analyses were used to create tail-o-grams in the corresponding manuscript. $* \star 3$. Compile nucleotide addition information to generate summaries of percent incorporation for each nucleotide.** Rename dataForGraph.txt files to include dataset name Place all files into the same folder with Total_Percent_nt_Analyses-vs1d.pl Perl script and SampleKey.out file This can be run on a Windows 7 or Windows 10 OS. Other operating systems were not tested. **Run Total_Percent_nt_Analyses-vs1d.pl** Uses dataForGraph.txt files output from PuppyTails program as input Uses SampleKey.out file to decode filenames/barcode numbers into sample names An example of a SampleKey.out file is shown here: https://github.com/melanieapreston/PuppyTails Column \#1 is a coded name for the sample; column \#2 is the actual sample name Outputs: A. Generates 2 files for each sample: 1. Samplename.out File that has removed repeated lines from dataForGraph.txt file 2. Samplename-averages.out File that summarizes 
total nucleotide addition metrics: -Sum Total unique tails -Unweighted Average nucleotide incorporation $\backslash$ (raw average of calculated percentages at each tail length) -Total of each nucleotide added -Total number of nucleotides added -Weighted Average nucleotide incorporation sum of each nucleotide added divided total of all nucleotides added B. Generates 2 files per set of data input, with metrics listed: 1. UnweightedTailCompSummaryForAllSamples.out --Sum total unique tails -Unweighted Average incorporation for each nucleotide -Average Tail Length -Percent of reporter tRNAs tailed 2.

WeightedTailCompSummaryForAllSamples.out -Sum Total unique tails -Total number of nucleotides added -Weighted Average incorporation for each nucleotide -Average Tail Length -Percent of reporter tRNAs tailed

\section{Figures}
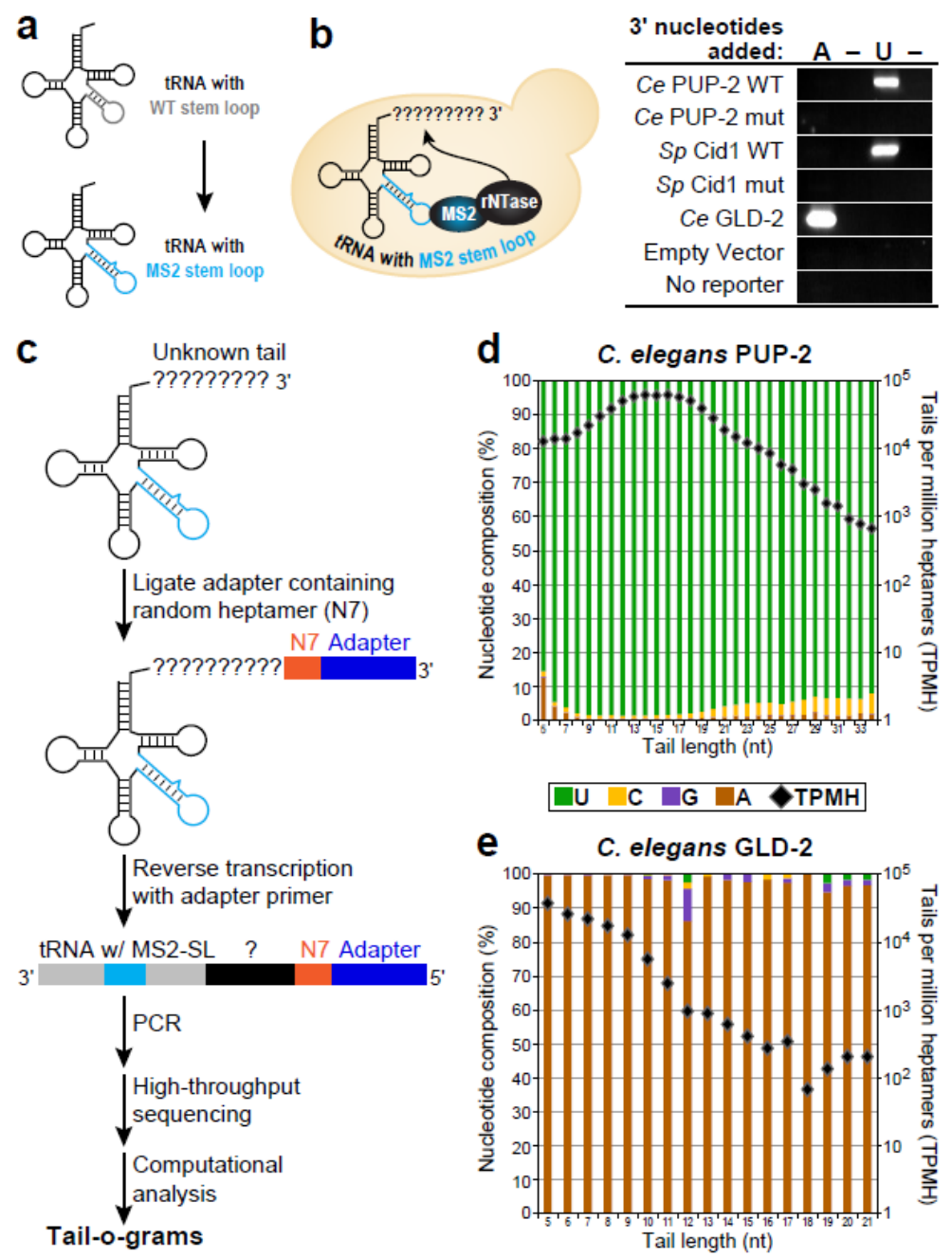

Figure 1

TRAID-Seq Overview *Figure 1. TRAID-Seq assay measures nucleotide addition activity in vivo.* (a, b) TRAID-Seq strategy. (a) tRNA^Ser(AGA)^ variable arm (gray) is mutated to an MS2 stem loop (cyan) to form the tRNA reporter. (b) Left, tRNA reporter is co-expressed with an MS2 coat protein-rNTase fusion in _S. cerevisiae_. The tethered rNTase adds nucleotides to the $3 \llbracket$ end of the tRNA. Right, RT-PCR analysis to detect A tails or U tails added by control rNTases, relative to empty vector or a no-reporter control. Lanes marked with a dash indicate reactions performed without reverse transcriptase. Representative gel image from 4 independent experiments. (c) Schematic of sample processing. DNA adapter (dark blue) with random heptamer (N7, orange) is ligated to total RNA extracted from samples, followed by reverse transcription, PCR, and high-throughput sequencing. (d, e) Tail-o-grams of nucleotides added by control rNTases. Data are shown for_C. elegans_PUP-2 (d) and_C. elegans_GLD-2 (e). Percent of each nucleotide at each tail length is color-coded and plotted on the left $\mathrm{y}$-axis; $\mathrm{U}$ (green), C (yellow), G (purple), A (brown). The number of tails detected per million random heptamers (TPMH) are indicated by gray diamonds and correspond to the log scale on the right $y$-axis. 
YEplac181 flanking vector sequences

TEF1 promoter

MS2 coat protein

Multiple cloning site

sv40 nuclear localization signal

RGS His 6 tag

YEplac181 upstream sequence

ttcacacaggaaacagctatgaccatgattacgccaagctt

TEF1 promoter

ACAATGCATACTTTGTACGTTCAAAATACAATGCAGTAGATATATTTATGCATATTACATATAATACATATCACATAGGAAGCAACAGC

CGCGTTGGACTTTTAATTTTCGAGGACCGCGAATCCTTACATCACACCCAATCCCCCACAAGTGATCCCCCACACACCATAGCTTCAAA

ATGTTTCTACTCCTTTTTTACTCTTCCAGATTTTCTCGGACTCCGCGCATCGCCGTACCACTTCAAAACACCCAAGCACAGCATACTAA

ATTTCCCCTCTTTCTTCCTCTAGGGTGTCGTTAATTACCCGTACTAAAGGTTTGGAAAAGAAAAAAGAGACCGCCTCGTTTCTTTTTCT

TCGTCGAAAAAGGCAATAAAAATTTTTATCACGTTTCTTTTTCTTGAAAATTTTTTTTTTTGATTTTTTTCTCTTTCGATGACCTCCCA

TTGATATTTAAGTTAATAAACGGTCTTCAATTTCTCAAGTTTCAGTTTCATTTTTCTTGTTCTATTACAACTTTTTTTACTTCTTGCTC

ATTAGAAAGAAAGCATAGCAATCTAATCTAAGTTTTAATTACAAAACTAGT

MS2 coat protein (no stop)

atggcttctaact tactcagttcgttctcgtcgacaatggcqgaactggcgacgtgactgtcgccccaagcaact tcoctaacggggt

cgctgaatggatcagctctaactcgcgt tcacaggcttacaaagtaacctgtagcgttcgtcagagctctgcgcagaagcgcaaataca

ccatcaaagtcgaggtgcctaaagtggcaacccagactgttggtggtgtagagcttcctgtagccgcatggcgttcgtacttaaatato gaactaaccattccaattttcgccacgaattccgactgcgagcttattgttaaggcaatgcaaggtctcctaaaagatggaaacccgat

tccetcggccatcgcagcaaactccggcatctacgtc

BamHI XmaI/SmaI NotI XbaI PstI KpnI

GGA TCC CCC GGG CGG CCG CCT TCT AGA CTG CAG GGT ACC

$\begin{array}{llllllllllll}P & K & K & K & R & K & V\end{array}$

CCA AAG AAG AAG AGA AAG GTT

R G S His6

AGA GGT TCT CAC CAC CAC CAC CAC CAC

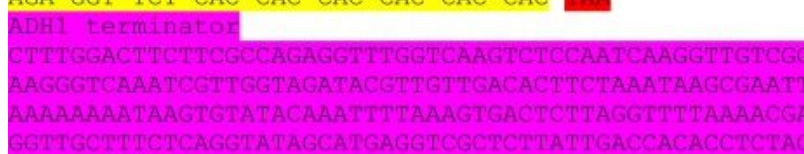

YEplac181 downstream sequence

CTCGAGcactggccgtcgttttacaacgtcgtgactgg

\section{Figure 2}

MS2 Cassette Annotated Insert

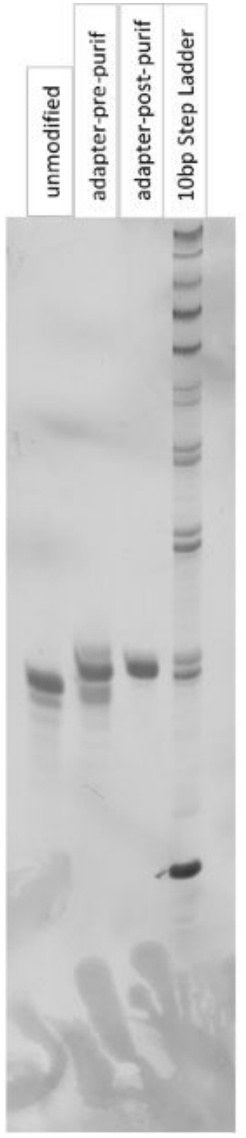

Figure 3 


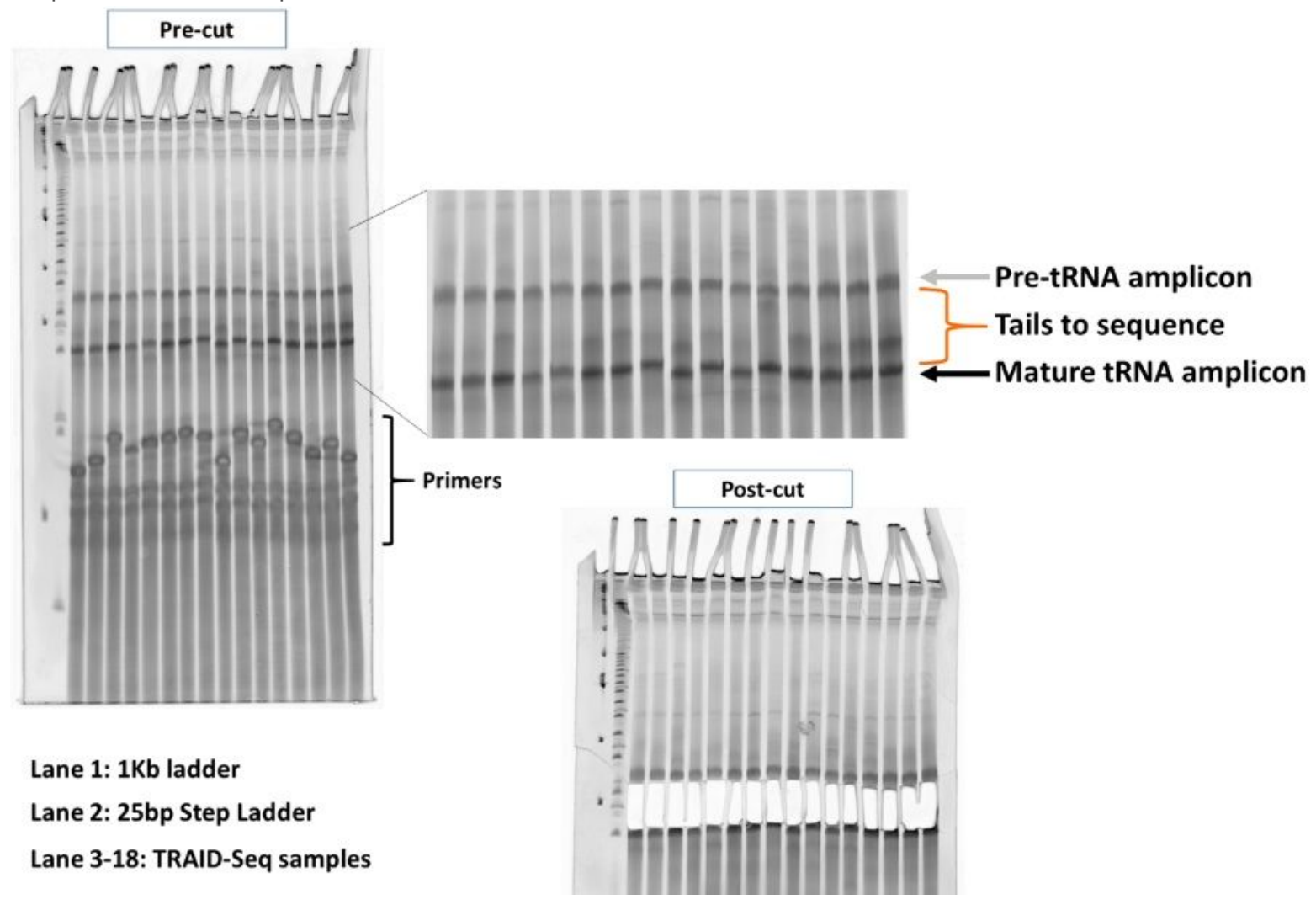

Figure 4

Gel Purification Guidance for TRAID-Seq Samples

\begin{tabular}{|l|l|}
\hline Reagent & Volume per 1 mL One Step Buffer \\
\hline 1 M Lithium Acetate & $200.6 \mu \mathrm{L}$ \\
\hline 60\% PEG 3350 & $662 \mu \mathrm{L}$ \\
\hline 1 M DTT & $100.3 \mu \mathrm{L}$ \\
\hline DMSO & $37.1 \mu \mathrm{L}$ \\
\hline
\end{tabular}

Figure 5

Table 1 One Step Buffer Recipe

\begin{tabular}{|c|c|c|}
\hline Reagent & Stock concentration & Final concentration \\
\hline SDS & $10 \%$ & $2 \%$ \\
\hline Tris pH 6.8 & $1000 \mathrm{mM}$ & $80 \mathrm{mM}$ \\
\hline Glycerol & $50 \%$ & $10 \%$ \\
\hline DTT* & $15.45 \%$ & $1.5 \%$ \\
\hline Bromophenol Blue & $1 \mathrm{mg} / \mathrm{mL}$ & $0.1 \mathrm{mg} / \mathrm{mL}$ \\
\hline $\mathrm{H}_{2} \mathrm{O}$ & & \\
\hline
\end{tabular}

*1 M DTT $=15.45 \% \mathrm{w} / \mathrm{vol}$ solution

ESB Buffer can be stored at $4^{\circ} \mathrm{C}$ for up to 2 months.

Figure 6

Table 2 ESB Buffer Recipe

\begin{tabular}{|c|c|c|}
\hline Reagent & $\begin{array}{l}\text { Stock } \\
\text { concentration }\end{array}$ & $\begin{array}{l}\text { Final } \\
\text { concentration }\end{array}$ \\
\hline $\mathrm{NaCl}$ & $5 \mathrm{M}$ & $0.5 \mathrm{M}$ \\
\hline Tris pH 7.5 & $1 \mathrm{M}$ & $0.2 \mathrm{M}$ \\
\hline EDTA & $0.5 \mathrm{M}$ & $0.01 \mathrm{M}$ \\
\hline SDS & & $1 \%$ \\
\hline $\begin{array}{l}\text { DEPC-treated ddH } \mathrm{H}_{2} \mathrm{O} \\
\text { (or Nuclease-free } \mathrm{H}_{2} \mathrm{O} \text { ) }\end{array}$ & & $\begin{array}{l}\text { To bring up } \\
\text { volume }\end{array}$ \\
\hline
\end{tabular}

\section{Figure 7}




\begin{tabular}{|c|c|}
\hline Reagent & Per sample \\
\hline $10 \times$ Turbo DNase Buffer & $10 \mu \mathrm{L}$ \\
\hline Turbo DNase I (Ambion) $20 \mathrm{U}$ & $10 \mu \mathrm{L}$ \\
\hline Extracted RNA & $50 \mu \mathrm{L}$ \\
\hline Nuclease-free $\mathrm{H}_{2} \mathrm{O}$ & $30 \mu \mathrm{L}$ \\
\hline Total volume & $100 \mu \mathrm{L}$ \\
\hline
\end{tabular}

Figure 8

Table 4 DNase Reaction Components

\begin{tabular}{|l|r|l|}
\hline Reagent & $\begin{array}{l}\text { Stock } \\
\text { concentration }\end{array}$ & $\begin{array}{l}\text { Final } \\
\text { Concentration }\end{array}$ \\
\hline $\begin{array}{l}\text { Ammonium } \\
\text { Acetate }\end{array}$ & $5 \mathrm{M}$ & $0.5 \mathrm{M}$ \\
\hline SDS & $10 \%$ & $0.1 \%$ \\
\hline EDTA & $500 \mathrm{mM}$ & \multicolumn{1}{|c|}{$5 \mathrm{mM}$} \\
\hline $\begin{array}{l}\text { Nuclease-free } \\
\mathrm{ddH}_{2} \mathrm{O}\end{array}$ & & $\begin{array}{l}\text { To bring up } \\
\text { volume }\end{array}$ \\
\hline
\end{tabular}

Figure 9

Table 5 Gel Extraction Buffer Recipe

\begin{tabular}{|c|c|c|c|}
\hline Reagent & $\begin{array}{l}\text { Stock } \\
\text { concentration }\end{array}$ & $\begin{array}{l}\text { Final } \\
\text { concentration }\end{array}$ & $19 \mu \mathrm{L}$ \\
\hline T4 RNA Reaction Buffer (NEB) & $10 \times$ & $1 x$ & $1.9 \mu \mathrm{L}$ \\
\hline PEG 8000 (NEB) & $50 \%$ & $10 \%$ & $3.8 \mu \mathrm{L}$ \\
\hline RNasIn (Promega Corp.) & & & $0.5 \mu \mathrm{L}$ \\
\hline Purified N7 Adenylated adapter & $37.7 \mathrm{pmol} / \mu \mathrm{L}$ & $20 \mathrm{pmol}$ & $0.53^{*} \mu \mathrm{L}$ \\
\hline T4 RNA ligase 2 trunc KQ (NEB) & & & $1 \mu \mathrm{L}$ \\
\hline DEPC dd $\mathrm{H}_{2} \mathrm{O}$ & & & $11.27^{*} \mu \mathrm{L}$ \\
\hline
\end{tabular}

${ }^{*}$ Volume will depend on concentration of purified adenylated adapter

\section{Figure 10}

Table 6 Ligation Reaction Components

\begin{tabular}{|c|c|c|c|}
\hline Reagent & $\begin{array}{l}\text { Stock } \\
\text { concentration }\end{array}$ & $\begin{array}{l}\text { Final } \\
\text { concentration }\end{array}$ & $20 \mu \mathrm{L}$ \\
\hline ImProm-II reaction buffer & $5 \times$ & $1 x$ & $4 \mu \mathrm{L}$ \\
\hline $\mathrm{MgCl}_{2}$ & $25 \mathrm{mM}$ & $1.5 \mathrm{mM}$ & $1.2 \mu \mathrm{L}$ \\
\hline dNTPs (Promega Corporation) & $10 \mathrm{mM}$ & $0.5 \mathrm{mM}$ & $1 \mu \mathrm{L}$ \\
\hline ImProm-II Reverse Transcriptase & & & $1 \mu \mathrm{L}$ \\
\hline DEPC $\mathrm{H}_{2} \mathrm{O}$ & & & $1.8 \mu \mathrm{L}$ \\
\hline RNA + primer & & & $11 \mu \mathrm{L}$ \\
\hline
\end{tabular}

\section{Figure 11}

Table 7 Reverse Transcription Reaction Components

\begin{tabular}{|l|r|r|r|}
\hline Reagent & $\begin{array}{l}\text { Stock } \\
\text { concentration }\end{array}$ & $\begin{array}{l}\text { Final } \\
\text { Concentration }\end{array}$ & $\begin{array}{l}\mathbf{1 2 . 5} \boldsymbol{\mu L} \\
\text { reaction }\end{array}$ \\
\hline dd $_{2} \mathrm{O}$ & & & $4.5 \mu \mathrm{L}$ \\
\hline GoTaq Green Master Mix (Promega Corp.) & $2 \times$ & $1 \times$ & $6.25 \mu \mathrm{L}$ \\
\hline 5' primer & $100 \mu \mathrm{M}$ & $1 \mu \mathrm{M}$ & $0.125 \mu \mathrm{L}$ \\
\hline 3' Primer (different index for each sample) & $100 \mu \mathrm{M}$ & $5 \mu \mathrm{M}$ & $0.63 \mu \mathrm{L}^{*}$ \\
\hline $\begin{array}{l}\text { RT reaction }(1 \mu \mathrm{L}) \mathrm{or} \\
\left.\text { [RNA ligation }(0.5 \mu \mathrm{L})+0.5 \mu \mathrm{L} \mathrm{H}_{2} \mathrm{O}\right]\end{array}$ & & & $1 \mu \mathrm{L}^{*}$ \\
\hline Total Volume: & & & $12.5 \mu \mathrm{L}$ \\
\hline
\end{tabular}

Figure 12

Table 8 PCR Reaction Mix

\begin{tabular}{|c|c|c|c|c|}
\hline Stage & Step & Temperature & Time & Cycles \\
\hline 1 & 1 & $95^{\circ} \mathrm{C}$ & 2 minutes & 1 \\
\hline 2 & 1 & $95^{\circ} \mathrm{C}$ & 30 seconds & 25 \\
\hline & 2 & $55^{\circ} \mathrm{C}$ & 45 seconds & \\
\hline & 3 & $72^{\circ} \mathrm{C}$ & 45 seconds & \\
\hline 3 & 1 & $72^{\circ} \mathrm{C}$ & 5 minutes & 1 \\
\hline
\end{tabular}

Hold $4^{\circ} \mathrm{C}$ 
Figure 13

Table 9 PCR Cycling Conditions

\begin{tabular}{|l|r|l|}
\hline Reagent & $\begin{array}{l}\text { Stock } \\
\text { concentration }\end{array}$ & $\begin{array}{l}\text { Final } \\
\text { concentration }\end{array}$ \\
\hline $\begin{array}{l}\text { Ammonium } \\
\text { Acetate }\end{array}$ & $5 \mathrm{M}$ & $1 \mathrm{M}$ \\
\hline Tris pH 8.0 & $1 \mathrm{M}$ & $10 \mathrm{mM}$ \\
\hline $\begin{array}{l}\text { Nuclease-free } \\
\text { dd } \mathrm{H}_{2} \mathrm{O}\end{array}$ & & $\begin{array}{l}\text { To bring up } \\
\text { volume }\end{array}$ \\
\hline
\end{tabular}

Figure 14

Table 10 TRAID-Seq PCR Amplicon Gel Elution Buffer Recipe 